\title{
Robotic-assisted laparoendoscopic single-site total omentectomy
}

\author{
Ji Geun Yoo, Jeong Yun Park, Keun Ho Lee
}

Department of Obstetrics \& Gynecology, Seoul St. Mary's Hospital, The Catholic University of Korea, Seoul, Korea

Objective: We report two cases of robotic-assisted laparoendoscopic single site (R-LESS) total omentectomy for early stage ovarian cancer in young patients.

Methods: Case 1. A 25-year-old woman was referred for Lt. ovarian serous borderline tumor diagnosed by LESS ovarian cystectomy. Ascites cytology exam revealed serous borderline tumor as well. On imaging studies, metastatic tumor was not observed. She was planned to receive R-LESS fertility- sparing staging surgery. Case 2. A 31-year-old woman was diagnosed with Rt. ovarian tumor during her regular gynecologic check-up. Pelvic MRI showed A $2.8 \mathrm{~cm}$ sized cystic and solid tumor without evidence of metastasis. She underwent LESS Rt. ovarian cystectomy. Serous borderline tumor was diagnosed, so we converted to R-LESS fertility-sparing staging surgery.

Results: Under Da-Vinci Xi single-site system, we were able to rotate the boom 180 degrees and perform total omentectomy. The operation time was 25 minutes and 27 minutes, respectively. There was almost no bleeding. Perioperative complications did not occur.

Conclusion: As previously reported, R-LESS staging surgery for ovarian malignant tumor is feasible in selected cases. As part of the procedure, we could demonstrate two cases of total omentectomy without complications.

Key Words: Ovarian neoplasms; Robotics; Omentectomy

- Received: October 16, 2019 • Revised: October 18, 2019 • Accepted: October 18, 2019

- Correspondening author: Keun Ho Lee

Department of Obstetrics \& Gynecology, Seoul St. Mary's Hospital, The Catholic University of Korea, 222 Banpo-daero, Seocho-gu, Seoul 06591, Korea

E-mail:hohoho@catholic.ac.kr

This is an Open Access article distributed under the terms of the Creative Commons Attribution Non-Commercial License (http://creativecommons.org/ licenses/by-nc/4.0) which permits unrestricted non-commercial use, distribution, and reproduction in any medium, provided the original work is properly cited. 